\title{
A Formação em Odontologia tem Atendido às Necessidades da Sociedade Brasileira?
}

\section{Training in Dentistry has Fulfilled Brazilian Society's Needs?}

\section{La Formación en Odontología ha Servido a las Necesidades de la Sociedad Brasileña?}

Danilo Cavalcante Fernandes ${ }^{1}$

Daniel Antunes Freitas ${ }^{2}$

Aldrya Ketly Pedrosa ${ }^{3}$

Elaine do Nascimento Silva ${ }^{4}$

\section{Resumo}

Introdução: Este estudo faz uma breve descrição da evolução histórica da Odontologia brasileira até os tempos atuais e os problemas da formação dos cirurgiões-dentistas, fazendo uma crítica acerca do papel dos docentes que ainda prezam pela formação tecnicista. Corpo do ensaio: Procura-se evidenciar a falta de conexão da formação tecnicista com as Diretrizes Curriculares Nacionais e, por conseguinte, com a Estratégia de Saúde da Família, afastando a Odontologia dos principais problemas e demandas sociais quando desconsidera o contexto em que os indivíduos estão inseridos. Conclusão: As conquistas da Odontologia foram muitas, mas longo ainda é o caminho a se percorrer para alcançar a excelência.

\section{Descritores: Saúde da Família; Odontologia Comunitária; Educação em Odontologia.}

\begin{abstract}
Introduction: This study is a brief description of the historical evolution of dentistry in Brazil untill today and the problems of dentists training, by doing a review on the teacher's role who still value the technical education. Body of the essay. It seeks to highlight the lack of connection of technical education with the National Curriculum Guidelines and therefore with the Family Health Strategy, which keeps Odontology away from key problems and social demands when it disregards
\end{abstract}


the context in which individuals are in.

Conclusion: The achievements of odontology were many, but long is still the way to go to achieve excellence

\section{Descriptors: $\quad$ Family Health;}

\section{Community Dentistry; Education}

Dental.

\section{Resumen}

Introducción: Este estudio es una breve descripción de la evolución histórica de la Odontología brasileña hasta los tiempos actuales, como también los problemas de la formación de los dentistas, haciendo una revisión del papel de los profesores que aún valoran la formación tecnicismos. Cuerpo del ensayo: Se pretende dar a conocer la falta de conexión con la formación tecnicista las Directrices Curriculares Nacionales y, por lo tanto, la Estrategia Salud de la Familia, la eliminación de los principales problemas y demandas sociales Odontología cuando se ignora el contexto en el que se insertan los individuos. Conclusión: Los logros de la odontología fueron muchos pero es largo todavía el camino a seguir para alcanzar la excelencia.

\section{Descriptores: Salud de la familia;}

Odontología comunidad; Educación en Odontología.

\section{Introdução}

A Odontologia vivenciou um longo processo evolutivo até chegar ao que hoje representa, saindo da era dos barbeiros para um momento mais científico: o dos cirurgiões-dentistas. Mas, como qualquer outra profissão, existem muitos problemas e desafios a serem enfrentados e o principal deles é o seu pouco alcance social.

Fazendo frente a esta questão, as Diretrizes Curriculares Nacionais $(\mathrm{DCN})^{(1)}$ trazem como perfil esperado do egresso do curso de Odontologia o de um cirurgião-dentista generalista, humanizado, socialmente sensível, ético, apto ao exercício da prática privada e da prática nos serviços públicos, e comprometido com a melhoria das condições de saúde bucal da população, visando uma maior observância aos determinantes sociais em saúde ${ }^{(2)}$.

Para o Sistema Único de Saúde (SUS) é mister que o modelo biomédico hegemônico seja redirecionado para o perfil do egresso de que trata as DCN durante a formação, já que é muito dispendioso tentar desconstruir perfis 
profissionais inadequados através de cursos de capacitação com o intuito de garantir o que as graduações não vem oferecendo ${ }^{(3)}$.

É fundamental que os docentes dos cursos de Odontologia sejam capazes de formar profissionais com perfis distintos dos seus próprios, mais de acordo com as diretrizes curriculares atuais e mais comprometidos com as populações mais carentes $^{(4)}$, que são maioria no país e não tem fácil acesso a tratamentos mais sofisticados.

Contextualizando, professores e alunos precisam realizar algumas rupturas na forma de conceber o mundo e a sua situação dentro dele ${ }^{(5)}$, inclusive conhecendo os diferentes ambientes onde os serviços estão inseridos e utilizando o levantamento situacional e epidemiológico como base para o planejamento de todas as ações.

Este estudo propõe uma discussão a respeito da formação do cirurgiãodentista; formação esta, que passou e ainda passa por grandes evoluções técnicas e tecnológicas, mas permanece aquém de atender a contento as demandas sociais.

\section{A odontologia, as demandas sociais e a integração ensino-serviço}

A odontologia vem galgando grandes conquistas no campo tecnológico, mas essas conquistas só são desfrutadas por pequena parcela da população brasileira, o que torna essa fatia do mercado mais rentável para os cirurgiões dentistas pelo motivo de os serviços serem oferecidos às populações mais abastadas e o que, ao que parece, mantém os dentistas na condição de puramente artista.

A odontologia social baseada na epidemiologia fica em segundo plano diante das tentações do mercado, induzindo quem tem emprego público na saúde bucal a estar sempre buscando novos conhecimentos, principalmente se neste emprego não tenham vínculo que garanta estabilidade e um plano de cargos carreiras e vencimentos que possibilite uma ascensão na carreira de forma digna ${ }^{(6)}$.

O slogan "A saúde começa pela boca" e propagandas de clínicas odontológicas divulgando uma "semiologia odonto-estomatológica" têm sido bastante utilizados (percebe-se muito na mídia televisiva) como que para garantir a definição de um diagnóstico fundamental sobre o processo saúde-doença, dando a entender que este processo se encontra afastado do contexto socioeconômico e 
Fernandes DA, Freitas DA, Pedrosa AK, Silva AN 73 A formação em Odontologia tem Atendido às Necessidades da Sociedade Brasileira? ${ }^{3}$

das relações intersubjetivas dos indivíduos ${ }^{(7)}$.

Com o advento do SUS e da Estratégia de Saúde da Família (ESF), a Odontologia tenta trilhar outros rumos e vem levando em conta o ambiente em que os indivíduos vivem e reconhecendo a família como espaço singular, visando o empoderamento desses indivíduos ao oferecê-los o domínio sobre suas vidas para tomarem decisões mais acertadas acerca de sua saúde ${ }^{(6)}$.

Assim, os cursos de graduação em Odontologia precisam estar voltados às necessidades da população mantendo a relação com o processo saúde-doença dos cidadãos, das famílias e das comunidades. Objetivando esse processo formativo, as DCN para os cursos de Odontologia $^{(1)}$ visam a formação de um cirurgião dentista generalista, humanista, com visão crítica e reflexiva para atuar em todos os níveis de atenção à saúde, com base no rigor técnico e científico, capacitado ao exercício de atividades referentes à saúde bucal da população, pautado em princípios éticos, legais e na compreensão da realidade social, cultural e econômica do seu meio, dirigindo sua atuação para a transformação da realidade, em benefício da sociedade.

Em 2005, com o Programa Nacional de Reorientação da Formação Profissional em Saúde (Pró-Saúde), pacto intersetorial entre os Ministérios da Saúde e da Educação, que prevê a educação permanente dos profissionais da área da saúde, visando a substituir o modelo hospitalocêntrico com foco na doença por um modelo mais humanizado com foco maior nas ações de promoção da saúde e de prevenção ${ }^{(7)}$, buscou-se preparar o profissional para atuar de maneira eficiente e eficaz, levando em conta a epidemiologia da área de adscrição dos seus pacientes, integrando ensino e $\operatorname{serviço~}^{(8)}$ e permitindo aos discentes vivenciarem experiências práticas no seu futuro campo de trabalho.

A integração ensino-serviço é de suma importância para que o aluno, dentro do seu contexto social, possa compreender o seu papel enquanto profissional de saúde. Para isto, as Instituições de Ensino Superior formadoras de recursos humanos não devem restringir seu papel social ao atendimento das demandas por serviços de saúde no seu interior, e sim, trazê-lo também para fora dele ${ }^{(9)}$. Apesar disso, os esforços para que esta integração 


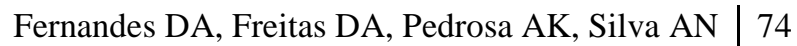
A formação em Odontologia tem Atendido às Necessidades da Sociedade Brasileira? ${ }^{4}$

ocorra ainda experimentam pouca sustentabilidade e as algumas atividades extramuros acabam dependendo mais da voluntariedade dos professores que as coordenam do que do apoio institucional e da participação do quadro docente como um todo ${ }^{(5)}$.

\section{A faculdade de odontologia e a estratégia de saúde da família}

Segundo as DCN do Curso de Graduação em Odontologia ${ }^{(1)}$, se faz necessária a construção de um novo perfil de cirurgião-dentista egresso para inserção no sistema de saúde vigente no país. Tal sistema tem passado por modificações nas últimas décadas, a saber: a criação do SUS na década de 80, a criação do Programa de Saúde da Família (PSF, hoje Estratégia de Saúde da Família - ESF) em 1994 (que veio com a intenção de reestruturar esse sistema) e, em seguida, o Ministério da Saúde criou o incentivo de saúde bucal que veio inserir a Odontologia neste Programa no ano 2000 visando melhorar as condições da saúde bucal da população brasileira, promovendo a integralidade dos cuidados garantindo a observância aos princípios do SUS ${ }^{(10)}$.

Para que as leis que regulamentam o SUS e seus princípios sejam cumpridas, se faz necessário a adoção de novas atitudes pelos vários sujeitos envolvidos. É preciso profissionais preparados para enfrentar as mudanças. Esse perfil profissional adequado às necessidades sociais nem sempre é priorizado pelas instituições de ensino superior, já que demanda uma estreita ligação entre o ensino e o serviço de saúde.

Com o intuito de romper com os modelos históricos de atenção à saúde, ineficientes e excludentes, baseados no curativismo e biologicismo, buscou, entre outras coisas, concretizar inovações educacionais nos cursos de graduação da área da saúde, dentre elas a construção de novas Diretrizes Curriculares Nacionais que não mais contemplam o modelo de currículo mínimo obrigatório na formação de profissionais $^{(10-11)}$.

A articulação entre as instituições de ensino superior e os serviços públicos de saúde tem impacto na formação dos recursos humanos para o SUS e se faz necessário que os serviços de saúde e a universidade dialoguem para se obter um ponto de interseção ${ }^{(12)}$.

Embora se observe que nos cursos de graduação de várias áreas da saúde, principalmente nos de Enfermagem e Medicina, vêm ocorrendo movimentos 
Fernandes DA, Freitas DA, Pedrosa AK, Silva AN 75

A formação em Odontologia tem Atendido às Necessidades da Sociedade Brasileira?

onde são repensados os modelos tradicionais de formação profissional, no curso de Odontologia existe um atraso nesses movimentos de mudanças pedagógicas, pois a maioria das escolas de Odontologia continua formando profissionais com ênfase no tecnicismo $^{(5)}$.

A formação do cirurgiãodentista se mantém fundamentada em um modelo de ensino que valoriza mais as ciências básicas do que a promoção e a prevenção, configurando um caminho de mudanças e desafios que precisa ser enfrentado pelas Instituições de Ensino Superior $^{(9)}$. É necessário que haja equilíbrio na integração das dimensões técnicas às ético-humanísticas para haver a formação de profissionais que preencham os requisitos formulados pelas $\mathrm{DCN}^{(13)}$.

Muito mais do que atender às DCN, deve-se buscar atender as necessidades do mundo moderno e uma coisa implica diretamente na outra e na consecução do ideário do SUS. Ocorre que no ingresso em uma equipe de Saúde Bucal, o profissional quase não traz da graduação uma experiência consistente, interdisciplinar e multiprofissional que é requisitada para o trabalho ${ }^{(12)}$.

Dois grandes obstáculos, facilmente perceptíveis, à plena adoção dos princípios universais de saúde coletiva para a Odontologia é que o docente tem sua formação profissional calcada em saberes técnicos, e sua formação pedagógica é resultante de iniciativa própria ou, de forma limitada, pelos programas de pós-graduação e com a especialização precoce e a grande valorização da técnica nos cursos de graduação em Odontologia, a ênfase dada à prevenção e promoção da saúde é limitada e houve uma diminuição da opção pela formação generalista ou de clínico geral $^{(13)}$.

A mudança de perfil do cirurgiãodentista decorrente da transição gradativa dos moldes curriculares centrados no paradigma técnicocientífico para uma visão integral e voltada para o coletivo é, sem dúvida, fundamental para a concretização das políticas de saúde bucal integradas à Estratégia de Saúde da Família ${ }^{(14)}$.

O mercado de trabalho em Odontologia vem sofrendo mudanças no decorrer dos anos. Cada vez mais os egressos procuram por empregos assalariados e, pelas dificuldades atuais do mercado de trabalho, até mesmo os profissionais que já exercem a prática liberal estão buscando os serviços públicos $^{(3,15)}$. Isto posto, e muito embora 
Fernandes DA, Freitas DA, Pedrosa AK, Silva AN 76

A formação em Odontologia tem Atendido às Necessidades da Sociedade Brasileira?

o SUS seja um importante mercado de trabalho para os cirurgiões-dentistas, principalmente com a inserção da saúde bucal na Estratégia de Saúde da Família, esse fato ainda não se fez suficiente para produzir o impacto esperado sobre o ensino de graduação $^{(5,16)}$.

O aumento das equipes de Saúde Bucal na Estratégia de Saúde da Família acabou por demonstrar as deficiências da formação do cirurgião-dentista, o que interfere na implementação do SUS, exigindo uma reorganização da prática odontológica. Grandes mudanças sociopolíticas, conceituais e pedagógicas se fazem necessárias. Existem novas demandas para o cirurgião-dentista $^{(16)}$. Embora seja imprescindível a competência do profissional em relação aos aspectos biológicos e clínicos, é cada vez mais necessário o desenvolvimento de competências no tocante às dimensões ética, política, econômica, cultural e social do seu trabalho, com foco na promoção da saúde em seu sentido integral $^{(3,17,18)}$.

Assim, a formação voltada para a priorização dos reais problemas sociais fica preterida e os egressos do curso de Odontologia que acabam por ingressar no serviço público reproduzem a forma de trabalho aprendida na graduação.

Deste modelo de atenção resultante de um currículo com ênfase na competência técnico-científica, especializada e com ênfase no curativo, com evidente separação entre as áreas básica e profissionalizante, é construído um perfil de profissional elitista, especializado e direcionado ao serviço privado. Daí surge a contradição entre o tipo de sistema e políticas públicas de saúde e a formação que o cirurgiãodentista está recebendo ${ }^{(9)}$.

Tudo o que vem sendo exposto não desmerece de forma alguma a parte curativa do atendimento. Ela é de grande importância tanto para garantir uma formação técnica adequada como para permitir excelência técnica nos tratamentos oferecidos aos pacientes, e o trabalho baseado no contexto social não vem a preteri-la, e sim dar-lhe um maior sentido permitindo um tratamento adequado aos problemas já instalados e tentando evitar mais desequilíbrios no processo saúde-doença.

Mas, se os discentes tendem a repetir o comportamento dos docentes, seria de extrema importância que os docentes tivessem maior contato com o SUS ou até mesmo um vínculo empregatício para conseguirem passar 
Fernandes DA, Freitas DA, Pedrosa AK, Silva AN $\mid 77$

A formação em Odontologia tem Atendido às Necessidades da Sociedade Brasileira?

para os discentes, de maneira mais eficiente, a forma de trabalho mais adequada a suprir as demandas da população.

\section{Conclusão}

É de grande importância a reflexão a respeito da capacitação pedagógica dos docentes. Se eles estão realmente preparados para desenvolver nos discentes o perfil profissional do cirurgião-dentista que a população necessita.

Aliada a isso, cabe a reflexão no que tange ao conhecimento dos docentes a respeito do SUS. É importante que as Universidades tenham professores que mantenham vínculo empregatício com o Sistema Único de Saúde (principalmente na Estratégia de Saúde da Família) pois a vivência desses profissionais aliada ao conhecimento, auxiliaria na inclusão do trabalho na atenção básica (as características, as limitações, as possibilidades) em suas atividades docentes.

As deficiências da formação do cirurgião-dentista tornaram-se perceptíveis com o aumento do número de Equipes de Saúde Bucal demandando um redirecionamento da prática odontológica. Mudanças sociopolíticas, conceituais e pedagógicas são necessárias para que esta formação esteja de acordo com o objetivado pelas DCN do curso de graduação em odontologia.

O docente é parte muito importante na formação do perfil do discente, pois podem produzir conhecimentos contextualizados e, assim, redirecionar a formação para o atendimento das demandas sociais, ensinando os discentes a buscarem o conhecimento dos determinantes de saúde da população que está sob sua responsabilidade passando para eles o entendimento de que a sua responsabilidade com o paciente não termina com o final do procedimento, sendo importante criar e manter ambientes saudáveis.

Ao continuar mantendo a distância entre ensino e as reais necessidades da sociedade, talvez não se consiga formar os profissionais mais adequados e capacitados para atuar no SUS. A grande valorização da técnica nos cursos de graduação em Odontologia pode vir a formar profissionais com perfil divergente daquele proposto pelas Diretrizes Curriculares Nacionais. É inegável as conquistas da Odontologia ao longo do 
tempo, desde quando se firmou enquanto profissão até os dias de hoje, mas inegável também é o longo caminho que ela ainda precisa percorrer para alcançar a excelência, ganhar mais espaço e valorização enquanto profissão de saúde e atender adequadamente aos clamores da sociedade.

\section{Referências}

1. Resolução CNE/CES n. 3, de 19 de fevereiro de 2002. Institui as Diretrizes Curriculares Nacionais do Curso de Graduação em Odontologia. Brasília; 2002 [acesso em 03 Out 2014]. Disponível em: http://portal.mec.gov.br /cne/arquivos/pdf/ CES032002.pdf

2. Badan DEC, Marcelo VC, RDG. Percepção e utilização dos conteúdos de saúde coletiva por cirurgiões-dentistas egressos da Universidade Federal de Goiás. Ciênc. saúde coletiva. [internet], 2010 [acesso em 28 Fev 2014]; 15(1): 1811-8. Disponível em: http://www. scielo.br/scielo.php?script=sci_arttext $\&$ pid $=$ S1413-81232010000700093\&lng= en. http://dx.doi.org/10.1590/S1413-812 32010000700093.

3. Moysés SJ. Políticas de saúde e formação de recursos humanos em Odontologia. Rev ABENO. 2004; 4(1): 30-7.

4. Reis SMAS, Cicillini GA. Práticas docentes no ensino odontológico: aproximações e distanciamentos das Diretrizes Curriculares Nacionais. Rev Ibero-Am Est Educação. 2011; 6(2)115.

5. Morita MC, Kriger L. Mudanças nos cursos de Odontologia e a interação com o SUS. Rev ABENO. 2004; 4(1): 17-21.

6. Faccin D, Sebold R, Carcereri DL. Processo de trabalho em saúde bucal: em busca de diferentes olhares para compreender e transformar a realidade. Ciênc. saúde coletiva. [internet], 2010 [acesso em 29 Set 2014]; 15(1): 164352. Disponível em: http://www.scielo. br/scielo.php?script=sci_arttext\&pid=S 1413-81232010000700076\&Ing=en.

7. Emmerich A, Castiel LD. A ciência odontológica, Sísifo e o "efeito camaleão". Interface (Botucatu). [internet], 2009 [acesso em 08 Fev 2014]; 13(29): 339-351. Disponível em: http://www.scielo.br/scielo.php?script=s ci_arttext\&pid=S1414-3283200900020 0008\&lng=en\&nrm=iso.

8. Portaria Interministerial n. 3.019, de 26 de novembro de 2007. Dispõe sobre o Programa Nacional de Reorientação da Formação Profissional em Saúde Pró-Saúde - para os cursos de graduação da área da saúde. Diário Oficial da União, 23 Out 2008.

9. Pinheiro FMC, Nóbrega-Therrien SM, Almeida MEL, Almeida MI. A formação do cirurgião-dentista no Brasil: contribuições de estudos para a prática da profissão. RGO-Revista Gaúcha. [internet], 2009 [acesso em 07 Fev 2014]; 57(1): 99-106. Disponível em: http://www.revistargo.com.br/ojs/in dex.php/revista/article/viewArticle/648.

10. Mattos GCM, Ferreira EF, Leite ICG, Greco RM. A inclusão da equipe de saúde bucal na Estratégia de Saúde da Família: entraves, avanços e desafios. Ciência e Saúde Coletiva. [internet], 2004 [acesso em 24 Set 2014]; 19(2): 373-82. Disponível em: http://www.scielo.com.br/scielo.php?scr 
ipt=sci_arttext\&pid=S1413-812320140 00200373\&ing=en.

11. Hora DL, Erthal RMC, Souza CTV, Hora EL. Propostas inovadoras na formação do profissional para o Sistema Único de Saúde. Trab educ saúde. [internet], 2013 [acesso em $11 \mathrm{Fev}$ 2014]; 11(3): 471-486. Disponível em: http://www.scielo.br/scielo.php?script=s ci_arttext\&pid=S1981-7746201300030 0002\&lng=pt\&nrm=iso.

12. Matos PES, Tomita NE. A inserção da saúde bucal no Programa Saúde da Família: da universidade aos polos de capacitação. Cad. Saúde Pública. [internet], 2004 [acesso em $07 \mathrm{Fev}$ 2014]; 20(6): 1538-44. Disponível em: http://www.scielo.br/scielo.php?script=s ci_arttext\&pid=S0102-311X200400060 0011.

13. Araújo RPC, Mello SMF. Cursos de Graduação em Odontologia: a Formação Docente. Pesq. Bras. Odontoped. Clin. Integr. [internet], 2011 [acesso em 07 Fev 2014]; 11(4): 615-25. Disponível em http://www.red alyc.org/pdf/637/63722200024.pdf.

14. Lenzi TL, Rocha RO, Dotto PP. Perfil dos cirurgiões-dentistas integrantes do Programa Saúde da Família em um município do sul do Brasil. Health Sci Inst. 2010; 28(2): 121-4.

15. Haddad AE, organizadora. A trajetória dos cursos de graduação na área da saúde: 1991-2004. Brasília: Instituto Nacional de Estudos e Pesquisas Educacionais Anísio Teixeira. 2006.

16. Araújo ME, Zilbovicius C. Interfaces da área da Educação e da Saúde na perspectiva da formação e do trabalho das equipes de Saúde da
Família - A formação acadêmica para o trabalho no Sistema Único de Saúde (SUS). In: Moisés ST, Kriger L, Moisés SJ, organizadores. Saúde Bucal das Famílias - trabalhando com evidências. São Paulo; Artes Médicas; 2008. p. 277-90.

17. Garbin CAS, Saliba NA, Moimaz SAS, Santos TS. O papel das universidades na formação de profissionais na área de saúde. Revista da ABENO. 2006; 6(1): 6-10.

18. Mendes RF, Moura MS, Prado Junior RR, Moura LFAD, Lages GP, Gonçalves MPR. Contribuição do Estágio Supervisionado da UFPI para formação humanística, social e integrada. Revista da ABENO. 2006; 6(1): 61-5. 